\title{
Chronic Fluoxetine Bidirectionally Modulates Potentiating Effects of Serotonin on the Hippocampal Mossy Fiber Synaptic Transmission
}

\author{
Katsunori Kobayashi, Yumiko Ikeda, Eisuke Haneda, and Hidenori Suzuki \\ Department of Pharmacology, Nippon Medical School, Tokyo 113-8602, Japan
}

\begin{abstract}
Selective serotonin reuptake inhibitors (SSRIs) have been used to treat various psychiatric disorders. Although the cellular mechanisms underlying amelioration of particular symptoms are mostly unknown, recent studies have shown critical importance of the dentate gyrus of the hippocampus in behavioral effects of SSRIs in rodents. Here, we show that serotonin potentiates synaptic transmission between mossy fibers, the sole output of the dentate granule cells, and CA3 pyramidal cells in mouse hippocampal slices. This potentiation is mediated by activation of 5- $\mathrm{HT}_{4}$ receptors and intracellular cAMP elevation. A chronic treatment of mice with fluoxetine, a widely used SSRI, bidirectionally modulates the 5-HT-induced potentiation: Fluoxetine enhances the potentiation induced by lower concentrations of serotonin, while attenuates that by the higher concentration, which represents stabilization of synaptic 5-HT action. In contrast to the chronic treatment, an acute application of fluoxetine in slices induces a leftward shift in the dose-response curve of the 5-HT-induced potentiation. Thus, acute and chronic fluoxetine treatments have distinct effects on the serotonergic modulation of the mossy fiber synaptic transmission. Exposure of mice to novel environments induces increases in locomotor activity and hippocampal extracellular 5-HT levels. In mice chronically treated with fluoxetine, the novelty-induced hyperactivity is reduced without significant alterations in home cage activity and motor skills. Our results suggest that the chronic fluoxetine treatment can stabilize the serotonergic modulation of the central synaptic transmission, which may contribute to attenuation of hyperactive behaviors.
\end{abstract}

Key words: hippocampus; mossy fiber; synaptic transmission; serotonin; SSRI; psychiatric disorder

\section{Introduction}

Selective serotonin reuptake inhibitors (SSRIs) have been widely used to treat various neurological disorders. Although SSRIs are often considered as the first-line treatment for mood and anxiety disorders, there is substantial heterogeneity in responsiveness of patients to SSRIs (Papakostas et al., 2008), and cellular mechanisms underlying their therapeutic effects and side effects still remain mostly unknown. Because it generally takes several weeks for the therapeutic effects of SSRIs to develop, adaptive changes in the central serotonergic system and/or other signaling systems have been thought to be involved (Taylor et al., 2005). To reveal the mechanism of action of SSRIs, it would be of critical importance to investigate cellular and synaptic changes associated with behavioral effects of chronic SSRI treatments in detail using experimental animals.

The hippocampus has been implicated in antidepressant and anxiolytic effects of SSRIs. There is dense projection of serotoner-

\section{Received Jan. 12, 2008; accepted May 12, 2008.}

This work was supported by the International Human Frontier Science Program Organization (K.K.), Japan Science and Technology Agency, Core Research for Evolutional Science and Technology (K.K.), and Grant-in-Aid for Science Research (C) 19590261 from the Ministry of Education, Culture, Sports, Science, and Technology, Japan (H.S.).

Correspondence should be addressed to Katsunori Kobayashi, Department of Pharmacology, Nippon Medical School, 1-1-5 Sendagi, Bunkyo-ku, Tokyo 113-8602, Japan. E-mail: kkatsu-tky@umin.ac.jp.

DOI:10.1523/JNEUROSCI.1656-08.2008

Copyright $\odot 2008$ Society for Neuroscience $\quad 0270-6474 / 08 / 286272-09 \$ 15.00 / 0$ gic fibers to the hippocampus (Jacobs and Azmitia, 1992), and serotonin [5-hydroxytriptamine (5-HT)] has been shown to modulate neuronal excitability and/or synaptic transmission in all subregions of the hippocampus (Segal, 1981; Otmakhov and Bragin, 1982; Roychowdhury et al., 1994; Tokarski and Bijak 1996; Mlinar et al., 2001; Otmakhova et al., 2005). The serotonergic system in the hippocampus is modulated by repeated SSRI treatments, which includes changes in effects of 5-HT application (Tokarski and Bijak 1996; Bijak et al., 1997) and serotonergic afferent stimulation (Chaput et al., 1991), downregulation of the 5-HT transporter (Benmansour et al., 2002), and enhanced tonic inhibition mediated by $5-\mathrm{HT}_{1 \mathrm{~A}}$ receptors (Haddjeri et al., 1998). Chronic SSRIs are also known to enhance proliferation of neuronal precursor cells in the dentate gyrus (Malberg et al., 2000), and this cytogenesis has been shown to be required for behavioral effects of SSRIs (Santarelli et al., 2003; Airan et al., 2007). Given the importance of the dentate gyrus in the behavioral effects of SSRIs, it is worth investigating whether the chronic SSRI treatment affects the signal transmission between the dentate gyrus and the hippocampus proper mediated by mossy fibers. The mossy fibers play critical roles in regulation of excitability and plasticity in the CA3 region (Henze et al., 2002; Kobayashi and Poo, 2004). We recently found that dopamine potentiates mossy fiber synaptic transmission via activation of $D_{1}$-like receptors (Kobayashi and Suzuki, 2007). Serotonin has been shown to enhance neuronal excitation evoked by mossy fiber stimulation 
(Otmakhov and Bragin, 1982), and a ligand binding study has demonstrated that $5-\mathrm{HT}_{4}$ receptors are strongly expressed along the mossy fiber tract (Vilaró et al., 2005). However, neither effects of 5-HT on the mossy fiber synaptic transmission nor receptors responsible for the effect of 5-HT have been elucidated. In the present study, we found that 5-HT potentiates the mossy fiber synaptic transmission via activation of $5-\mathrm{HT}_{4}$ receptors in mice. We further examined a possible association between the serotonergic modulation of the mossy fiber synaptic transmission and behavioral changes induced by the chronic SSRI treatment.

\section{Materials and Methods}

Animals. Adult male mice ( $8-15$ weeks of age) were used in all experiments. To characterize effects of 5-HT on the mossy fiber synaptic transmission, outbred ddY mice were initially used (see Figs. 1-3; supplemental Fig. 1, available at www.jneurosci.org as supplemental material). Because outbred mice are less likely to have strain-specific features than inbred mice, outbred mice were considered to be suitable for the initial study. Essential points were then reexamined using inbred C57BL/6J mice (supplemental Fig. 2, available at www.jneurosci.org as supplemental material). Effects of fluoxetine treatments on behaviors were examined using inbred C57BL/6J mice (see Fig. 4), because inbred mice show lower behavioral variability than outbred mice in general. All other experiments were also performed using C57BL/6 mice (see Figs. 5-7; supplemental Fig. 3, available at www.jneurosci.org as supplemental material).

Electrophysiology. Mice were decapitated under halothane anesthesia and both hippocampi were isolated. Transverse hippocampal slices $(370-380 \mu \mathrm{m})$ were cut using a tissue slicer (Vibratome 3000plus; Vibratome) in ice-cold saline (see below). Slices were then incubated for 30 $\min$ at $30^{\circ} \mathrm{C}$ and maintained in a humidified interface holding chamber at room temperature $\left(24-27^{\circ} \mathrm{C}\right)$ before recordings.

Electrophysiological recordings were made from slices in a submersion-type chamber superfused at $2 \mathrm{ml} / \mathrm{min}$ with saline composed of the following (in $\mathrm{mm}$ ): $125 \mathrm{NaCl}, 2.5 \mathrm{KCl}, 1.0 \mathrm{NaH}_{2} \mathrm{PO}_{4}, 26.2$ $\mathrm{NaHCO}_{3}, 11$ glucose, $2.5 \mathrm{CaCl}_{2}, 1.3 \mathrm{MgCl}_{2}$ (equilibrated with $95 \%$ $\mathrm{O}_{2} / 5 \% \mathrm{CO}_{2}$ ). Bath temperature was maintained at $27.0-27.5^{\circ} \mathrm{C}$ using an automated temperature controller. Bipolar tungsten stimulating electrodes were placed in the dentate gyrus granule cell layer to activate mossy fibers. Field EPSPs (fEPSPs) arising from mossy fiber synapses were recorded from the stratum lucidum using a glass pipette filled with $2 \mathrm{~m} \mathrm{NaCl}$. Single electrical stimulation was delivered at a frequency of $0.05 \mathrm{~Hz}$ unless otherwise specified. The method for identifying and analyzing mossy fiber fEPSPs was described previously in detail (Kobayashi et al., 1999; Kobayashi and Suzuki, 2007). Briefly, in the present study, large paired-pulse facilitation $(>2.5$-fold) was routinely used as a criterion for the mossy fiber input. This criterion was verified by $>85 \%$ block of fEPSP amplitude by an agonist of group II mGluRs (metabotropic

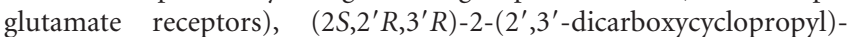
glycine (DCG-IV) $(1 \mu \mathrm{M})$ (see Fig. $1 A$ ). The block by DCG-IV was the sole criterion for the mossy fiber inputs in whole-cell recordings and in electrophysiological examination of fluoxetine-treated mice (see below). Whole-cell recordings were made from CA3 pyramidal cells by using the blind whole-cell patch-clamp technique. The membrane potential was clamped at +35 to $+40 \mathrm{mV}$ using a pipette filled with a solution composed of the following (in mM): $140 \mathrm{CsCl}, 20 \mathrm{HEPES}, 8 \mathrm{NaCl}$, $2 \mathrm{MgATP}$, $0.3 \mathrm{Na}_{2} \mathrm{GTP}, 0.5$ EGTA, $0.05 \mathrm{CaCl}_{2}$, pH adjusted to 7.2 with $\mathrm{CsOH}$. EPSCs mediated by NMDA receptors were recorded in the voltage-clamp mode in the presence of 2,3-dioxo-6-nitro-1,2,3,4-tetrahydrobenzo[f]quinoxaline-7-sulfonamide (NBQX) $(1 \mu \mathrm{M})$ and picrotoxin $(100 \mu \mathrm{M})$. Series resistance $(10-20 \mathrm{M} \Omega)$ was monitored during the recording, and data were discarded when it changed $>15 \%$. All recordings were made using a Multiclamp 700B amplifier (Molecular Devices), filtered at $2 \mathrm{kHz}$ and stored in a personal computer via an interface (digitized at $5-10 \mathrm{kHz}$ ). All procedures were approved by the institutional Animal Care and Use Committee.

Home cage activity monitoring and fluoxetine treatment. Mice (8 weeks of age) were singly housed in the institutional standard condition (14:10 light/dark cycle; lights on at 6:00 A.M. through 8:00 P.M.) and the horizontal activity of mice in the home cages was monitored (ImageJ HC8; O'Hara and Co., Ltd.). All mice received food and water ad libitum, and fluoxetine was applied in the drinking water (Dulawa et al., 2004). The fluoxetine solutions were prepared every other day. The concentration of fluoxetine was determined based on the averaged daily amount of the water consumption so that mice would take $10 \mathrm{mg} \cdot \mathrm{kg}^{-1} \cdot \mathrm{d}^{-1}$ of fluoxetine and adjusted for a gradual drift in the amount of the water consumption during the course of the treatment. Although mice were housed in isolation in cages with opaque walls, the activity of mice during the light period is supposed to be affected by external stimuli such as noise made by workers in the animal facility. Therefore, in quantitative analyses, effects of fluoxetine on the activity during the dark period (nocturnal activity) were assessed (see Fig. 4A).

Behavioral experiments. Mice were transferred to a behavioral testing room at 10:30 A.M. They were allowed to acclimatize to the environment of the room for at least $3 \mathrm{~h}$ before starting behavioral tests at 1:30 P.M. Room temperature was kept at $24 \pm 0.5^{\circ} \mathrm{C}$. Locomotor activity was examined using an open-field test. The open-field apparatus composed of opaque white walls and a floor $(50 \times 50 \times 50 \mathrm{~cm})$ was illuminated at an intensity of 40 lux. Each mouse was placed in the center of the open-field arena, and then locomotor (horizontal) activity was monitored for 20 min via a CCD camera positioned above the apparatus. The ambulatory distance and relative time spent in the central zone were measured. To calculate relative time spent in the center, the floor of the apparatus was divided into 25 squares and time spent in the central nine squares was measured. Vertical activity was assessed by measuring the number and duration of infrared photobeam interruption. The open-field arena was thoroughly cleaned with a hypochlorous acid solution $(\sim 15 \mathrm{ppm}), \mathrm{pH}$ $5-6.5$, before each test. All records were stored on a PC and analyzed using software based on the public domain NIH Image (Image OF; O'Hara and Co., Ltd.).

Motor skills were tested with an accelerating rotarod test. The rotarod apparatus consisted of a rotating rod $3.2 \mathrm{~cm}$ in diameter and $8.6 \mathrm{~cm}$ in width) and an infrared photobeam sensor to detect the fall of the mouse from the rod (O'Hara and Co., Ltd.). Mice had to walk forward to maintain balance on the rod. In each trial, the mouse was placed on the rod rotating at $4 \mathrm{rpm}$ and allowed to habituate for $30 \mathrm{~s}$. The speed of the rotation then increased to $40 \mathrm{rpm}$ over $5 \mathrm{~min}$ and the latency to fall was measured. The trials were repeated five times at an interval of $60-70 \mathrm{~min}$.

In vivo microdialysis. Three to $10 \mathrm{~d}$ before microdialysis experiments, a guide canula (AG-4; EICOM) was stereotaxically implanted into the right ventral hippocampus of mice (10-13 weeks of age) according to the atlas of Paxinos and Franklin (2004): anterior-posterior, $-2.8 \mathrm{~mm}$ from the bregma; lateral, $3.0 \mathrm{~mm}$ from the midline; dorsal-ventral, $-2.5 \mathrm{~mm}$ from the skull surface. On the day of the experiment, a microdialysis probe with 2-mm-long membrane (A-I-4-2; EICOM) was placed in the ventral hippocampus through the implanted guide canula. The probe was then continuously perfused with Ringer's solution ( $147 \mathrm{~mm} \mathrm{NaCl}, 4$ $\mathrm{mm} \mathrm{KCl}, 3 \mathrm{~mm} \mathrm{CaCl}$ ) at a rate of $1.0 \mu \mathrm{l} / \mathrm{min}$ using a gastight syringe pump (ESP-64; EICOM). Mice were placed in the home cages and allowed to move freely using the free-moving system with a rotating swivel (TCS2-23; Tsumura). Microdialysis sampling was started $>2 \mathrm{~h}$ after the probe insertion. Perfusate was collected every $5 \mathrm{~min}$ and automatically injected into an HPLC equipped with an electrochemical detection (HTEC-500; EICOM). Serotonin was separated on a column (EICOMPAK pp-ODS $30 \times \phi 4.6 \mathrm{~mm}$; EICOM) kept at $25^{\circ} \mathrm{C}$ and detected using EPC-500 (EICOM) with applied potential of $400 \mathrm{mV}$. The mobile phase composed of $0.1 \mathrm{M}$ sodium phosphate buffer, $\mathrm{pH} 6.0$, containing 500 $\mathrm{mg} / \mathrm{L}$ sodium 1-decanesulfonate, $50 \mathrm{mg} / \mathrm{L}$ EDTA-2Na, and $1 \%$ methanol. Serotonin concentrations in the perfusate were calculated by Power Chrom software (EICOM). The probe placement in each mouse was verified by examining the coronal brain sections after the experiment. Only data obtained from mice with the proper probe placement were included.

Drugs. Fluoxetine, dopamine, and picrotoxin were purchased from Wako Pure Chemical Industries. 5-Fluoro-2-methoxy-[1-[2-[(methylsulfonyl)amino] ethyl]-4-piperidinyl]-1 $H$-indole-3-methylcarboxylate sulfamate (GR1 25487), zacopride, DCG-IV, NBQX, and (2R)-(+)-8-hydroxy-2-(di- $n$ - 
propylamino)tetralin (8-OH-DPAT) were from Tocris Bioscience. 4-[(3-Butoxy-4-methoxyphenyl)methyl]-2-imidazolidinone (Ro-20-1724) was from Calbiochem. Serotonin, forskolin, $N$ - $[2-$ [4-(2-methoxyphenyl)-1-piperazinyl] ethyl]$N$ - 2 - pyridinylcyclohexanecarboxamide (WAY100635), and (1-butyl-4-piperidinyl)methyl-8-amino-7-chloro-1,4-benzodioxane-5-carboxylate hydrochloride (SB204070) were from Sigma-Aldrich.

Statistics. All values are expressed as means \pm SEM. Statistical significance was evaluated by two-tailed Student's $t$ test, paired $t$ test, one-way ANOVA, or two-way repeated-measures ANOVA with the significance level of $p<0.05$.

\section{Results}

Serotonin-induced potentiation of mossy fiber synaptic transmission

We first examined whether 5-HT can modulate mossy fiber-CA3 synaptic transmission using mouse hippocampal slices. This initial characterization was performed using outbred ddY mice (see Materials and Methods). Bath-applied 5-HT at $5 \mu \mathrm{M}$ induced robust potentiation of the amplitude of fEPSPs at the mossy fiber synapse (to $157.2 \pm 8.1 \%$ of baseline; $n=7$ ) (Fig. $1 A, B$ ). This potentiation was mostly reversible (Fig. $1 B$ ) and increased in magnitude in a concentration-dependent manner (Fig. 1D). When 5-HT was applied at $30 \mu \mathrm{M}$, the amplitude of fEPSPs started to decline or desensitize during 5 min application (Fig. 1C). The apparent desensitization was also observed during the prolonged application of a lower concentration $(5 \mu \mathrm{M})$ of 5 -HT (data not shown). In voltage-clamped CA3 pyramidal cells, 5-HT potentiated the amplitude of EPSCs recorded in the presence of picrotoxin, a blocker of $\mathrm{GABA}_{\mathrm{A}}$ receptors (Fig. $1 E, F)$. This potentiation was accompanied by a reduction in paired-pulse facilitation ratios of the EPSC amplitude (to $87.3 \pm 4.0 \%$ of baseline ratio; $n=6 ; p<$ 0.05 ) (Fig. $1 E$ ). The reduction of the synaptic facilitation was also observed during the 5-HT-induced potentiation of fEPSPs (data not shown). These results indicate that 5-HT induces potentiation of the excitatory synaptic transmission at the mossy fiber synapse that is independent of the synaptic inhibition and is probably expressed through an increase in presynaptic transmitter release probability.

Next, we pharmacologically examined the subtype of 5-HT receptors responsible for the synaptic potentiation. It has been shown that $5-\mathrm{HT}_{4}$ receptors are abundantly expressed in the dentate gyrus and along the mossy fiber tract (Vilaró et al., 2005). A selective blocker of 5- $\mathrm{HT}_{4}$ receptors, GR125487 (20 nM), completely suppressed the 5-HT-induced potentiation and unveiled small, but significant, synaptic depression (to $90.5 \pm 2.5 \%$ of baseline; $n=8 ; p=0.0085$ ) (Fig. 2A). GR125487 had no significant effects on the basal synaptic transmission or paired-pulse
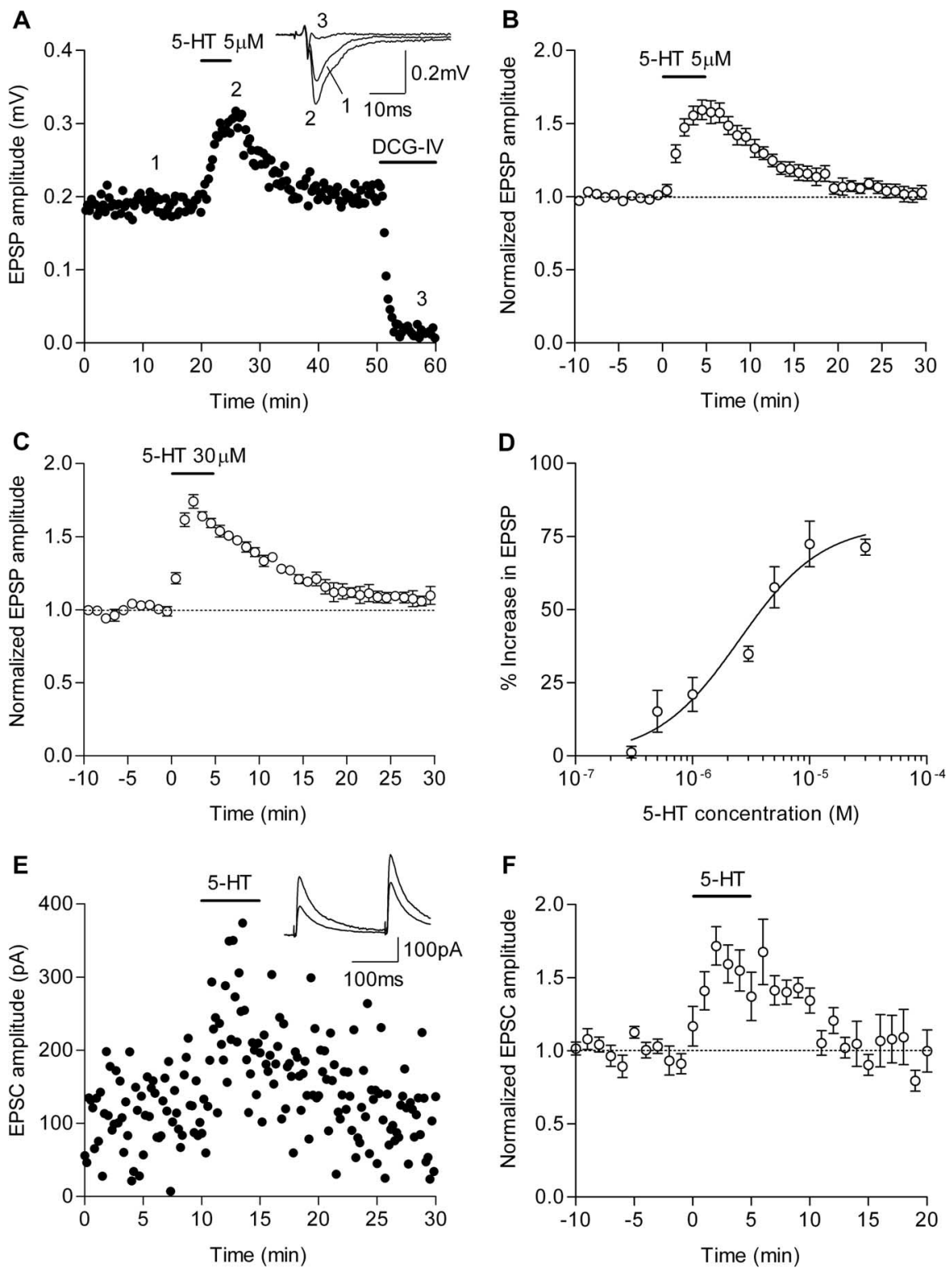

Figure 1. Potentiation of mossy fiber synaptic transmission by $5-\mathrm{HT}$. A, Potentiation and suppression of mossy fiber fEPSPs by bath-applied 5-HT (5 $\mu \mathrm{M})$ and DCG-IV $(1 \mu \mathrm{M})$, respectively. Drugs were applied at the horizontal bars. Inset, Sample traces are averages of 10 consecutive fEPSPs recorded at the times indicated by the numbers. $B, C$, Pooled data showing the potentiation of fEPSPs by 5 -HT at $5 \mu \mathrm{m}(\boldsymbol{B})$ and $30 \mu \mathrm{m}(\boldsymbol{C})$. D, Dependence of the synaptic potentiation on 5 -HT concentrations $(n=4-8)$. The $\mathrm{EC}_{50}$ value and Hill coefficient are $2.5 \mu \mathrm{m}$ and 1.2, respectively. $\boldsymbol{E}$, Potentiation of mossy fiber NMDA EPSCs by $5-\mathrm{HT}(10 \mu \mathrm{M})$. Paired before and during 5-HT application. $\boldsymbol{F}$, Pooled data showing the potentiation of NMDA EPSCs by $10 \mu \mathrm{m} 5-\mathrm{HT}$ (to $154.1 \pm 13.3 \%$ of baseline; $n=6$ ). Error bars indicate SEM.

facilitation (data not shown). Another selective antagonist of $5-\mathrm{HT}_{4}$ receptors, SB204070 (50 $\left.\mathrm{nM}\right)$, similarly suppressed the 5 -HT-induced potentiation ( $90.8 \pm 3.6 \%$ of baseline; $n=5)$. An agonist of $5-\mathrm{HT}_{4}$ receptors, zacopride $(5 \mu \mathrm{M})$, induced robust potentiation that was also blocked by GR125487 (Fig. 2C). These results indicate that the 5 -HT-induced potentiation is mediated by $5-\mathrm{HT}_{4}$ receptors. The 5 -HT-induced synaptic depression observed in the presence of GR 125487 is likely mediated by $5-\mathrm{HT}_{1 \mathrm{~A}}$ receptors, because it was blocked by a selective $5-\mathrm{HT}_{1 \mathrm{~A}}$ receptor antagonist, WAY100635 (50-100 nM) (100.7 $\pm 2.8 \%$ of baseline; $n=6)\left(\right.$ Fig. $2 \mathrm{~B}$ ), and a selective $5-\mathrm{HT}_{1 \mathrm{~A}}$ receptor agonist, $8-\mathrm{OH}$ DPAT $(5 \mu \mathrm{M}$ ), also induced small synaptic depression (to $92.5 \pm$ $2.4 \%$ of baseline; $n=7$ ). The zacopride-induced potentiation 
A

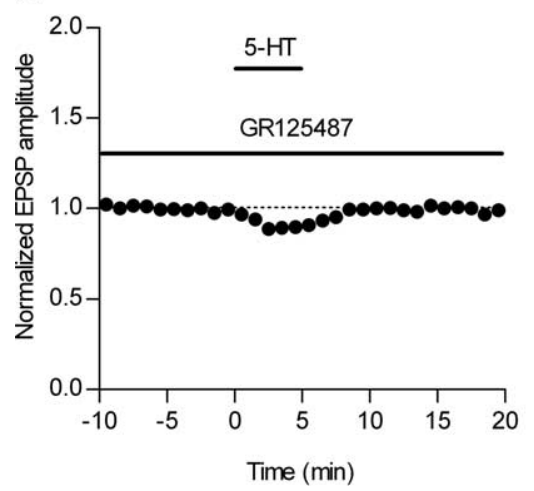

B

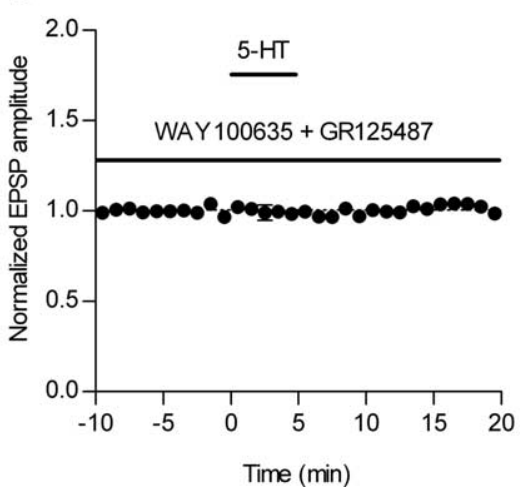

C

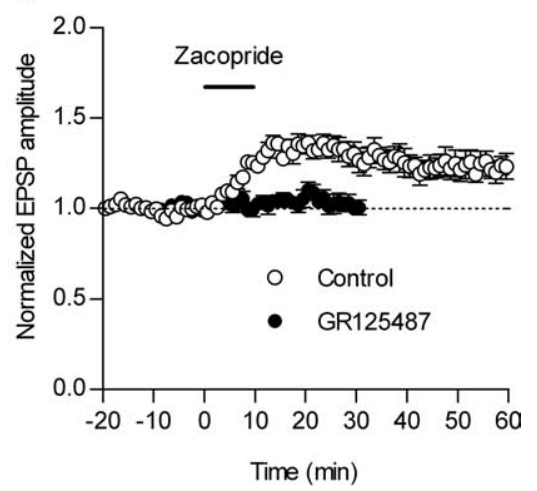

Figure 2. Mediation of 5 -HT-induced potentiation by 5 -HT ${ }_{4}$ receptors. $A$, In the presence of GR125487 ( $20 \mathrm{~nm}$ ), the potentiation of fEPSPs induced by $5 \mu \mathrm{m} 5$-HT was abolished ( $n=8$ ) and small depression was unveiled. $\boldsymbol{B}$, Lack of significant effects of 5 -HT in the presence of GR125487 (20 nM) and WAY100635 (50-100 nM) ( $n=6)$. C, Zacopride (5 $\mu$ m) potentiated the amplitude of fEPSPs to $135.2 \pm 3.9 \%$ of the baseline (open circles; $n=6$ ). Zacopride failed to induce potentiation in the presence of GR125487 (filled circles; $n=5$ ). Error bars indicate SEM.

was smaller in magnitude than that by 5 -HT, which is consistent with the previous study reporting the partial agonist-like nature of zacopride (Elswood et al., 1991), and poorly recovered after prolonged washout of the drug. GR125487 applied 15 min after the zacopride application failed to reverse this lasting phase of the zacopride-induced potentiation (data not shown). These differences in the effects between 5-HT and zacopride might represent distinct active receptor states induced by different ligands (Kenakin, 2003).

Because $5-\mathrm{HT}_{4}$ receptors are coupled to Gs-adenylate cyclase cascades (Barnes and Sharp, 1999), we next examined the involvement of cAMP in the 5-HT-induced potentiation. Bathapplied forskolin, an adenylate cyclase activator, induced remarkable potentiation of the mossy fiber synaptic transmission (Fig. 3A) as reported previously (Weisskopf et al., 1994; Kobayashi and Suzuki, 2007). The magnitude of the 5-HT-induced potentiation was greatly reduced in the presence of forskolin compared with that before the forskolin application in the same slice (Fig. $3 A, B$ ), suggesting that forskolin occluded the potentiating effect of 5-HT. In the presence of forskolin, long-lasting depression followed the 5-HT-induced potentiation (Fig. 3B). Although we did not further characterize this depression, it seemed to be associated with the $5-\mathrm{HT}_{1 \mathrm{~A}}$-dependent synaptic depression (see C57BL/6J experiments described below). We then examined effects of an inhibitor of cAMP-specific phosphodiesterases, Ro-20-1724. Ro-20-1724 by itself induced small synaptic potentiation $(115.3 \pm 3.5 \%$ of baseline; $n=6 ; p=$ 0.0071 ) as previously reported (Kobayashi and Suzuki, 2007), and also concomitantly reduced the paired-pulse facilitation ratio $(96.4 \pm 1.0 \%$ of baseline ratio; $n=6 ; p=0.013)$. In the presence of Ro-20-1724, the 5-HT-induced potentiation was clearly augmented (Fig. 3C). In the absence of forskolin or Ro20-1724, the effects of 5-HT were indistinguishable between the first and second application (Fig. 3D). We recently found that dopamine also induces synaptic potentiation at the mossy fiber synapse via activation of Gs-coupled $\mathrm{D}_{1}$-like receptors (Kobayashi and Suzuki, 2007). In the presence of dopamine, the magnitude of the 5-HT-induced potentiation was greatly reduced (supplemental Fig. 1, available at www.jneurosci.org as supplemental material), suggesting that 5-HT shares the signaling pathway with dopamine for the generation of the synaptic potentiation. Together, these results suggest that the 5-HT-induced potentiation is mediated by the intracellular cAMP elevation.

We then reexamined the 5-HT-induced potentiation of mossy fiber synaptic transmission using C57BL/6J mice, because effects of the SSRI fluoxetine on behaviors and the mossy fiber synapse were investigated in this inbred strain (see below). In C57BL/6] mice, bath-applied 5-HT induced robust potentiation at the concentration range similar to that in ddY mice (supplemental Fig. $2 \mathrm{~A}$, available at www.jneurosci.org as supplemental material). Although the potentiation in $\mathrm{C} 57 \mathrm{BL} / 6 \mathrm{~J}$ was slightly larger in magnitude than that in $\mathrm{ddY}$ mice, it was completely suppressed by GR125487 (supplemental Fig. 2B, available at www. jneurosci.org as supplemental material) and also by SB204070 (data not shown). Bath-applied zacopride induced clear synaptic potentiation that was also suppressed by GR125487 (supplemental Fig. 2C, available at www.jneurosci.org as supplemental material). Furthermore, in the presence of forskolin, the 5-HTinduced potentiation was greatly reduced (supplemental Fig. 2D, available at www.jneurosci.org as supplemental material). These results suggest that 5-HT potentiates mossy fiber synaptic transmission through the activation of $5-\mathrm{HT}_{4}$ receptors and the intracellular cAMP elevation in C57BL/6J mice as well as in ddY mice. Unlike ddY mice, synaptic depression was not clearly seen either in the presence of GR125487 or in forskolin. Thus, 5-HT has only potentiating effects on mossy fiber synapse in C57BL/6J mice.

\section{Effects of chronic fluoxetine treatment on behavior and mossy fiber synaptic transmission}

The 5-HT-induced potentiation found in this study would be a potential site for action of chronic SSRIs. Therefore, we next examined effects of fluoxetine, a widely used SSRI, on the mossy fiber synaptic transmission and also on behaviors using C57BL/6 J mice. We first characterized behavioral effects of the fluoxetine treatment. Because behavioral effects of antidepressant drugs including SSRIs depend on strains of mice used and doses of the drugs (Lucki et al., 2001; Dulawa et al., 2004), the behavioral analysis is supposed to be prerequisite for evaluating functional meanings of cellular changes caused by these drugs in a given condition. While monitoring activity of mice in their home cages over 2 weeks, fluoxetine was applied in the drinking water at a dose of $10 \mathrm{mg} \cdot \mathrm{kg}^{-1} \cdot \mathrm{d}^{-1}$. During the fluoxetine treatment, the nocturnal home cage activity was slightly reduced, but there was no statistically significant difference between the control and treated mice (Fig. 4A). There was a trend that the activity at the beginning of the dark period is reduced in the treated mice (Fig. $4 B$ ). After the treatment for 2 weeks, we performed a series of behavioral tests. In the fluoxetine-treated mice, the open-field 
locomotor activity was clearly reduced $(8896 \pm 456 \mathrm{~cm}$ in control; $6681 \pm 386 \mathrm{~cm}$ in fluoxetine; $n=8$ each; $p=0.0023$ ) (Fig. $4 C$ ) with no significant changes in the time spent in the center of the field $(17.3 \pm 4.0 \%$ in control; $18.7 \pm 1.8 \%$ in fluoxetine) or in the vertical activity (data not shown). Motor skills assessed by a rotarod test were not significantly affected in the fluoxetinetreated mice (Fig. 4D). There were no detectable changes in anxiety-related behaviors assessed by a light/dark transition test and an elevated plus-maze test or a depression-related behavior assessed by a forced-swim test (supplemental Fig. 3, available at www.jneurosci.org as supplemental material). These results suggest that the chronic fluoxetine treatment at 10 $\mathrm{mg} \cdot \mathrm{kg}^{-1} \cdot \mathrm{d}^{-1}$ in $\mathrm{C} 57 \mathrm{BL} / 6 \mathrm{~J}$ mice primarily reduces the activity of these mice in novel environments or reactivity of the mice to changes in environments.

Using these fluoxetine-treated mice, we next examined whether the 5-HT-induced potentiation of the mossy fiber synaptic transmission was changed after the treatment. In the fluoxetine-treated mice, the effect of $1 \mu \mathrm{M} 5$-HT was markedly augmented (Fig. 5A). Conversely, however, the synaptic potentiation induced by $5 \mu \mathrm{M}$ 5 -HT was significantly reduced in the treated mice (Fig. 5B). As shown in Figure $5 C$, the dependence of the synaptic potentiation on 5-HT concentrations was greatly blunted in the fluoxetine-treated mice compared with the control mice. There were no changes in the magnitude of paired-pulse facilitation at an interval of 50 $\mathrm{ms}(2.75 \pm 0.11$ in control; $2.67 \pm 0.09$ in fluoxetine) or $1 \mathrm{~s}(1.60 \pm 0.02$ in control; $1.58 \pm 0.02$ in fluoxetine) $(n=8-12)$. The basal synaptic efficacy evaluated by the ratio of the fEPSP amplitude to presynaptic fiber volley amplitude was also unaffected (data not shown). Therefore, the alterations in the 5-HT effects are not attributable to changes in the transmitter release probability from the mossy fiber terminals.

We also examined acute effects of fluoxetine on the 5-HT-induced potentiation in hippocampal slices. Bath-applied fluoxetine at 1 and $3 \mu \mathrm{M}$ enhanced the synaptic potentiation induced by $1 \mu \mathrm{M} 5-\mathrm{HT}$ in a concentration-dependent manner (Fig. $6 A, C)$. However, fluoxetine did not significantly affect the peak magnitude of the potentiation induced by $5 \mu \mathrm{M} 5$-HT (Fig. $6 B, C)$, although it accelerated a rise of the potentiation. As shown in Figure $6 D$, the acute fluoxetine application at $3 \mu \mathrm{M}$ induced a leftward shift in the dose-response curve of the 5-HTinduced potentiation by about an order of magnitude, which is clearly different from the effects caused by the chronic fluoxetine treatment (Fig. 5). Thus, the acute and chronic fluoxetine treatments have distinct effects on the serotonergic modulation of the mossy fiber synaptic transmission.
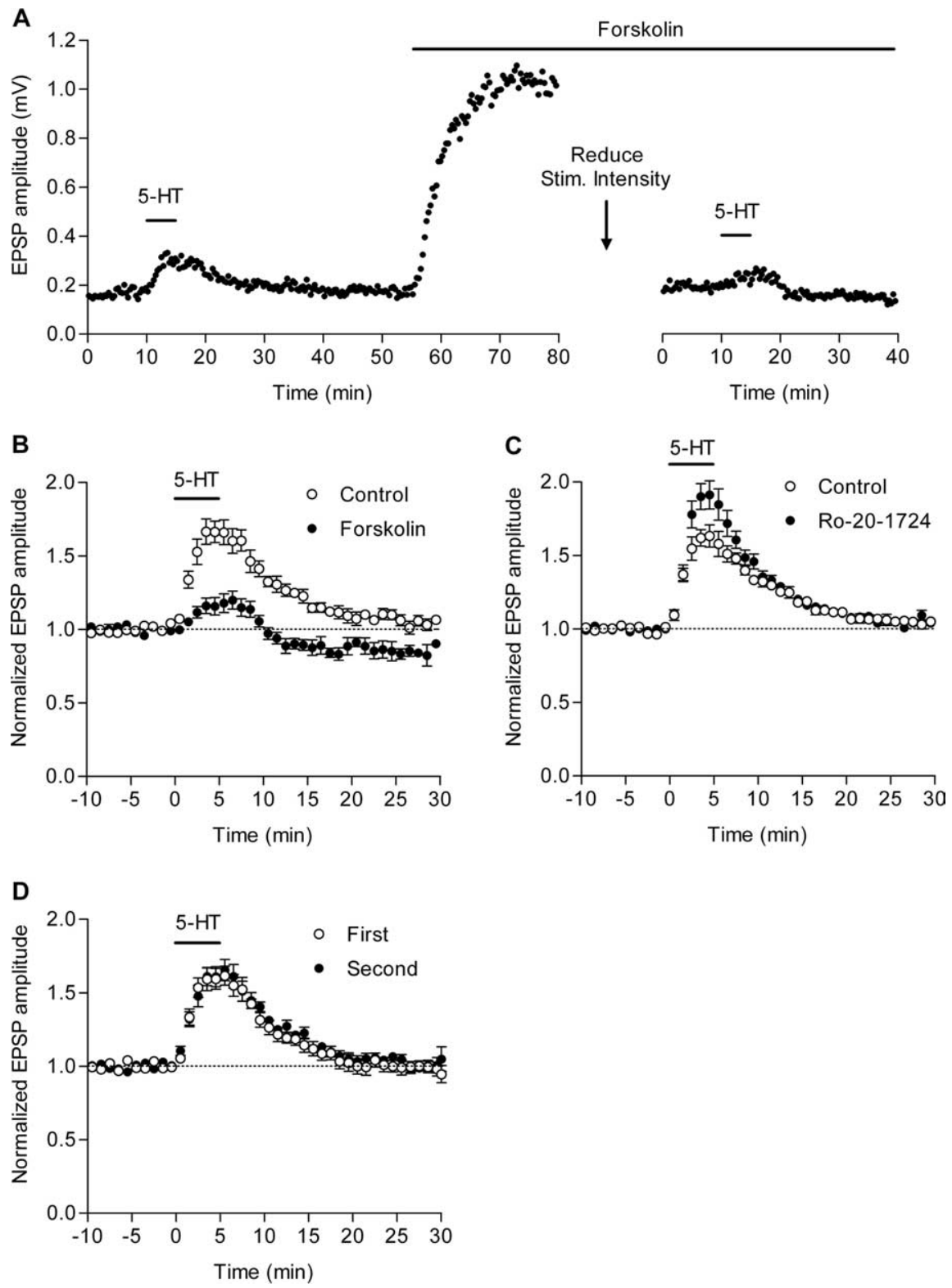

Figure 3. Mediation of 5-HT-induced potentiation by cAMP. A, Suppression of the 5-HT-induced potentiation by forskolin. Serotonin $(5 \mu \mathrm{M})$ was applied before and during application of forskolin $(10 \mu \mathrm{M})$ in the same slice. To avoid EPSP saturation during forskolin application, stimulus intensity was reduced (downward arrow) and the amplitude of fEPSPs was approximately matched to that before forskolin application. $\boldsymbol{B}$, Pooled data showing the suppression of the 5 -HT-induced potentiation by forskolin (to $166.4 \pm 8.9$ and $116.6 \pm 6.1 \%$ of baseline before and during forskolin, respectively; $p=0.0055 ; n=5$ ). C, Pooled data showing enhancement of the 5 -HT-induced potentiation by Ro-20-1724 (20 $\mu \mathrm{M})$ (to $161.0 \pm 7.7$ and $188.6 \pm 10.1 \%$ of baseline before and during Ro-20-1724, respectively; $p=0.0015 ; n=6$ ). $D$, The second application of 5 -HT without forskolin or Ro-20-1724 induced potentiation indistinguishable from the first one $(n=5)$. Error bars indicate SEM.

Extracellular 5-HT levels in hippocampus of behaving mice The significant effect of chronic fluoxetine on the open-field activity suggests that the serotonergic transmission in vivo, possibly in the hippocampus, may be activated in novel environments. To directly test this possibility, we examined by in vivo microdialysis whether extracellular levels of 5-HT in the hippocampus are changed on exposure to novel environments in behavioral testing naive mice. The hippocampal extracellular 5-HT level was quite stable while mice were in their home cages (Fig. 7). When mice were transferred to the open field as in the behavioral experiments, the extracellular 5-HT level was markedly increased (Fig. 7). The 5-HT level started to decline while mice were placed in the 

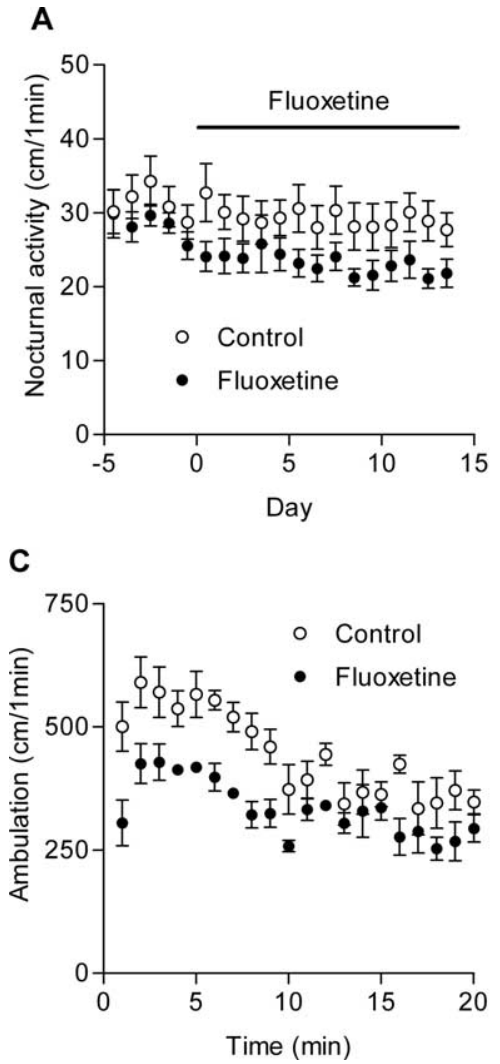

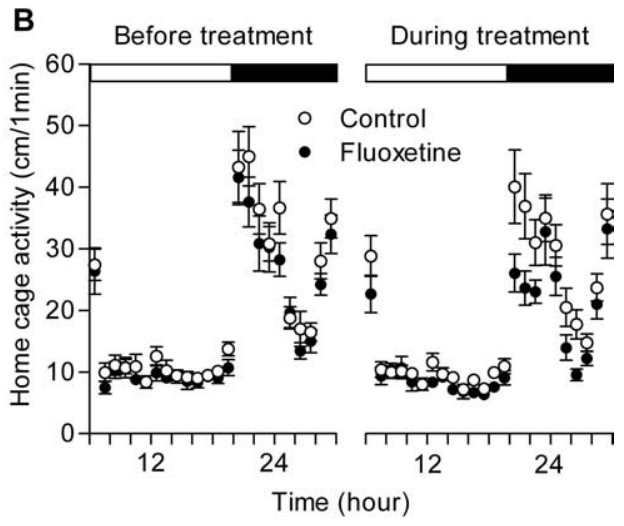

D

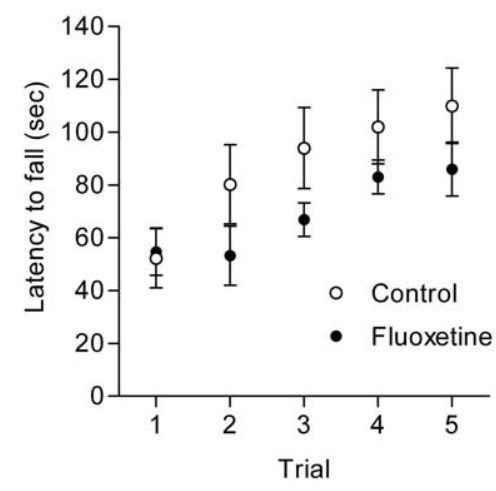

Figure 4. Reduction of open-field activity after chronic treatment of mice with fluoxetine. $\boldsymbol{A}$, Effects of orally applied fluoxetine on nocturnal home cage activity $(n=8$ each). $\boldsymbol{B}$, Patterns of home cage activity during $24 \mathrm{~h}$ before and during the fluoxetine treatment. The light and dark periods are indicated by open and filled bars on the top, respectively. $C$, Reduction of open-field activity in the fluoxetine-treated mice ( $n=8$ each). $\boldsymbol{D}$, Lack of significant effects of fluoxetine on motor skills of mice. The latency to fall from the rod in the accelerating rotarod test is shown. Error bars indicate SEM.

open field and there was no marked increase when they were returned to the home cages. These results suggest that the serotonergic transmission in the hippocampus is enhanced when mice are exposed to novel environments.

\section{Discussion}

In the present study, we found that 5-HT potentiates the hippocampal mossy fiber-CA3 synaptic transmission via activation of $5-\mathrm{HT}_{4}$ receptors. This finding is consistent with the previous observations that 5-HT increases neuronal excitation evoked by mossy fiber stimulation (Otmakhov and Bragin, 1982) and that the high level of $5-\mathrm{HT}_{4}$ receptor ligand binding is localized along the mossy fiber pathway (Vilaró et al., 2005). The chronic fluoxetine treatment bidirectionally modulated the 5-HT-induced potentiation in a manner dependent on the concentrations of 5-HT. In the fluoxetine-treated mice, the activity in the novel environment, but not in the familiar environment, was reduced. Our results suggest that the chronic fluoxetine treatment can stabilize the serotonergic modulation of the mossy fiber synaptic transmission, which could be a potential cellular basis for the attenuation of the novelty-induced hyperactivity.

The hippocampus proper receives direct and indirect synaptic inputs from the entorhinal cortex. The direct cortical input is inhibited by 5-HT (Otmakhova et al., 2005), whereas the indirect input via the dentate gyrus is potentiated at the mossy fiber synapse. The synaptic transmission between hippocampal pyramidal cells is unaffected or inhibited by 5-HT (Tokarski and Bijak 1996; Mlinar et al., 2001). Serotonin also changes excitability of the pyramidal cells and its immediate effects are mostly inhibitory (Segal, 1981; Roychowdhury et al., 1994; Tokarski and Bijak, 1996). Thus, in the presence of 5-HT, a relative contribution of the mossy fiber input to excitation of the pyramidal cells is increased. In other words, 5-HT highlights the cortical information that has been processed by the dentate gyrus. It has been proposed that the dentate granule cells and CA3 pyramidal cells are involved in disambiguation of differences in sensory input patterns. Although minimal changes in the environment influence correlated firing patterns of granule cells, relatively large changes in the environment can recruit distinct cell populations in the CA3 region (Leutgeb et al., 2007). The mossy fiber input plays critical roles in regulation of excitability of CA3 pyramidal cells (Henze et al., 2002; Kobayashi and Poo, 2004). Because changes in environments can increase hippocampal extracellular 5-HT levels (Fig. 7), the 5-HT-induced potentiation of the mossy fiber synaptic transmission may contribute to such environmentdependent changes in activity of CA3 pyramidal cells.

The chronic treatment of animals with SSRIs or antidepressant drugs has diverse effects on the central serotonergic system (Stahl, 1998; Taylor et al., 2005). In the present study, the chronic fluoxetine treatment caused the bidirectional change in the 5-HT-induced potentiation: The potentiation induced by the lower concentrations of 5-HT was enhanced, whereas that induced by the higher concentration of 5-HT was reduced (Fig. 5). The enhancement of the potentiation by the lower concentrations of 5-HT can be explained by downregulation of the 5-HT transporters (Benmansour et al., 2002), because the acute block of the 5-HT transporters by bath-applied fluoxetine had similar enhancing effects. However, if the downregulation of the transporters solely occurs, the dose-response curve of the 5-HT-induced potentiation is supposed to shift leftward as seen in the acute block of the transporters (Fig. 6). Thus, the transporter downregulation cannot solely explain the bidirectional change in the 5-HT effects observed after the chronic fluoxetine treatment. The reduction of the potentiation by the higher concentration of 5-HT could be attributable to downregulation of $5-\mathrm{HT}_{4}$ receptors. It is also possible that upregulation of phosphodiesterases (Ye et al., 2000) contributes to the reduction of the potentiation, because the potentiating effect of 5-HT was augmented by the phosphodiesterase inhibitor (Fig. 3C).

We recently showed that the mossy fiber synaptic transmission is associated with the open-field activity (Kobayashi et al., 2006). Consistently, in the present study, we found that the chronic fluoxetine treatment modifies the open-field locomotor activity as well as the 5-HT-induced potentiation of the mossy fiber synaptic transmission. Hippocampal serotonin levels are positively correlated with animal activity (Linthorst et al., 1994). A systemic application of $5-\mathrm{HT}_{4}$ receptor antagonists reduces locomotor activity (Fontana et al., 1997) and mice deficient for $5-\mathrm{HT}_{4}$ receptors show greatly reduced open-field activity (Compan et al., 2004). Hippocampal infusion of 5- $\mathrm{HT}_{4}$ agonists and 

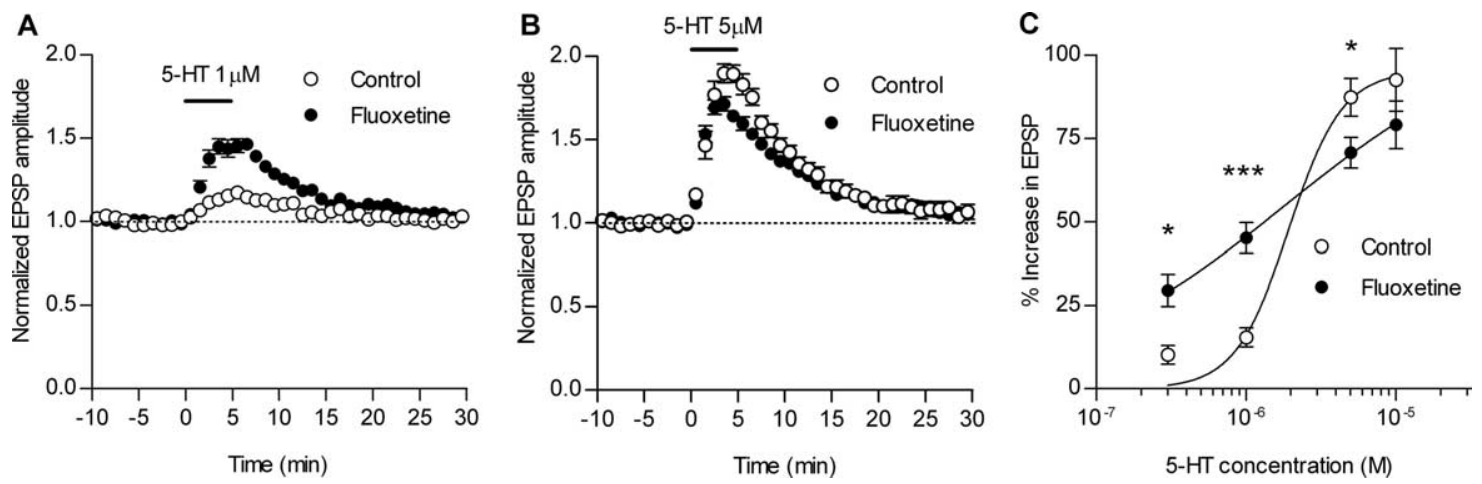

Figure 5. Bidirectional effects of chronic fluoxetine on 5 -HT-induced potentiation. $A$, Enhancement of the synaptic potentiation induced by $1 \mu \mathrm{m} 5$-HT in fluoxetine-treated mice (control, $n=$ 7; fluoxetine, $n=9$ ). $\boldsymbol{B}$, Reduction of the synaptic potentiation induced by $5 \mu \mathrm{m} 5$ - HT in fluoxetine-treated mice (control, $n=8$; fluoxetine, $n=9$ ). $\boldsymbol{C}$, A change in the dependence of the synaptic potentiation on 5-HT concentrations in fluoxetine-treated mice $(n=4-9)\left(\mathrm{EC}_{50}: 1.9 \mu \mathrm{m}\right.$ in control, $1.8 \mu \mathrm{m}$ in fluoxetine; Hill coefficient: 2.4 in control, 0.6 in fluoxetine). ${ }^{*} p<0.05 ;{ }^{* * *} p<0.0005$. Error bars indicate SEM.
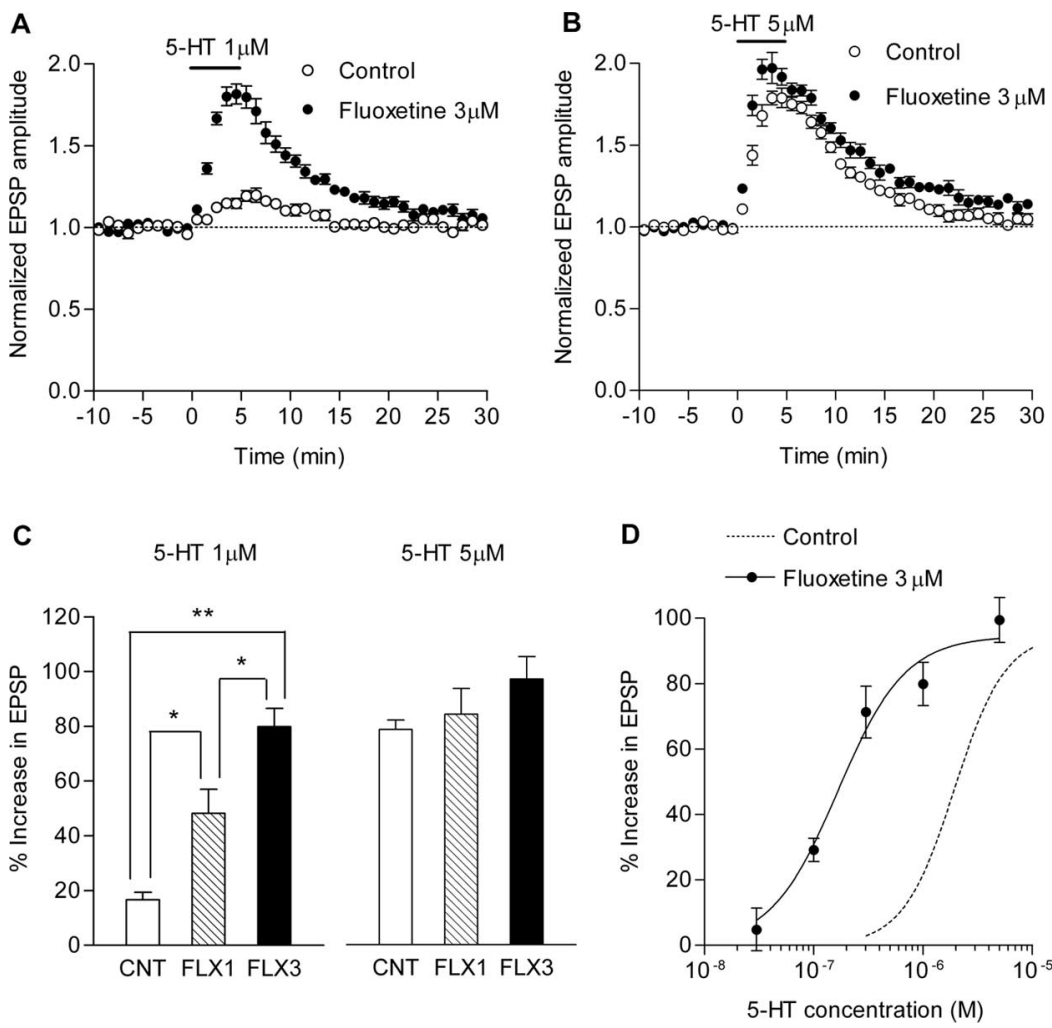

Figure 6. Effects of acute fluoxetine on 5 -HT-induced potentiation. $A$, Effects of $3 \mu \mathrm{m}$ acute fluoxetine on the synaptic potentiation induced by $1 \mu \mathrm{m} 5-\mathrm{HT}$ (control, $n=5$; fluoxetine, $n=7$ ). B, Effects of $3 \mu \mathrm{m}$ acute fluoxetine on the synaptic potentiation induced by $5 \mu \mathrm{m} 5-\mathrm{HT}$ ( $n=6$ each). C, Summary data showing effects of $1 \mu \mathrm{M}$ (FLX1) and 3 $\mu \mathrm{m}$ (FLX3) acute fluoxetine on 5-HT-induced potentiation $(n=5-7) .{ }^{*} p<0.05$; ${ }^{* *} p<0.005$. D, A leftward shift of dose-response curve for 5 -HT-induced potentiation caused by $3 \mu \mathrm{m}$ acute fluoxetine $(n=4-7)\left(\mathrm{EC}_{50}, 0.17 \mu \mathrm{m}\right.$; Hill coefficient, 1.4). The dashed line shows the control dose-response curve in supplemental Figure $2 A$ (available at www.jneurosci.org as supplemental material). Error bars indicate SEM.

antagonists induces hyperlocomotion and hypolocomotion, respectively (Takahashi et al., 2002). The 5-HT-induced potentiation of the mossy fiber synaptic transmission was exclusively mediated by $5-\mathrm{HT}_{4}$ receptors (Fig. 2; supplemental Fig. 2, available at www.jneurosci.org as supplemental material). Together, these lines of evidence suggest that the activation of $5-\mathrm{HT}_{4}$ receptors at the mossy fiber synapse can lead to an increase in the locomotor activity. The greatly blunted dose-response curve in the fluoxetine-treated mice (Fig. $5 C$ ) indicates that the mossy fiber synapse is less sensitive to changes in 5-HT concentrations around the apparent $\mathrm{EC}_{50}$ value in these mice than in the control mice. The exposure of mice to the open field increased the locomotor activity (Fig. 4) and the extracellular 5-HT level in the hippocampus (Fig. 7). The reduced sensitivity of the mossy fiber synapse to the 5-HT elevation may play a part in the reduction of the open-field activity in the fluoxetine-treated mice. The central serotonergic adaptation has been hypothesized to be involved in delayed therapeutic effects of antidepressant drugs. The leading hypothesis is that the chronic antidepressant causes desensitization or downregulation of inhibitory autoreceptors, which leads to tonic enhancement of serotonergic transmission (Stahl, 1998). This model can well explain elevation of basal levels of 5-HT (Yoshioka et al., 1995) and enhancement of 5-HT $\mathrm{HA}_{1 \mathrm{~A}}$ receptor-mediated tonic inhibition (Haddjeri et al., 1998) in the hippocampus after chronic antidepressant treatments. The elevation of basal 5-HT levels may cause desensitization of $5-\mathrm{HT}_{4}$ receptors at the mossy fiber synapse, which may help attenuate the effects of the novelty-induced rise in 5-HT on the mossy fiber synapse.

It has been shown that behavioral effects of antidepressant drugs including fluoxetine depend on the strain of mice (Lucki et al., 2001; Dulawa et al., 2004). In the present study, we did not observe clear effects of chronic fluoxetine on the depression-related behavior in C57BL/6 mice. Dulawa et al. (2004) also showed that the chronic oral fluoxetine treatment at the same dose as used in our study did not affect the depression-related behavior in $\mathrm{C} 57 \mathrm{BL} / 6$ mice, but caused a reduction in the open-field activity, although it was less obvious than the effect observed in our study. They further showed that the same treatment in BALB/c mice did not affect the openfield locomotor distance, but reduced the depression- and anxiety-related behaviors. Using BALB/c mice, we also examined whether the chronic fluoxetine treatment changes the 5-HTinduced potentiation of the mossy fiber synaptic transmission, but failed to detect robust effects (our unpublished observation). In $\mathrm{BALB} / \mathrm{c}$ mice, the neurogenesis in the dentate gyrus is neither 


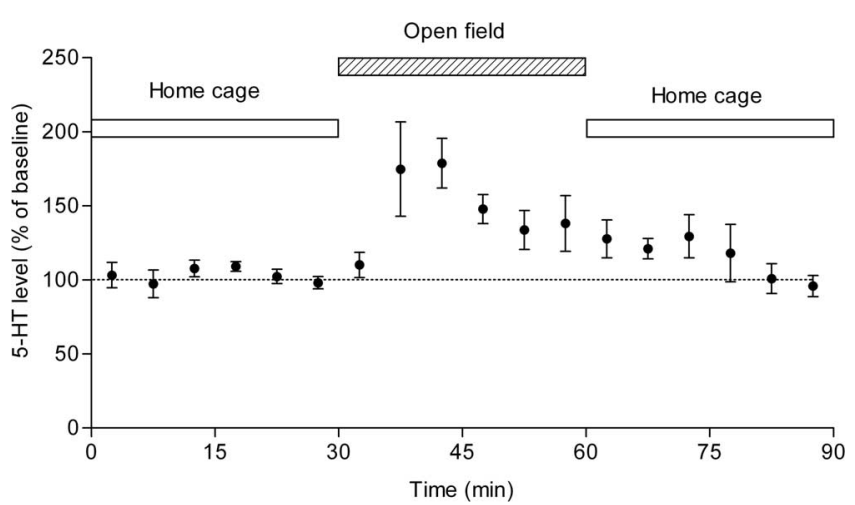

Figure 7. Effects of open-field exposure on extracellular 5-HT levels in the hippocampus. Mice were transferred from the home cage to the open field and returned to the home cage after $30 \mathrm{~min}$ as indicated by the bars on the top. The hippocampal extracellular 5-HT levels were continuously measured through the procedure. Data are given as percentages of the mean values before the open-field exposure $(n=5)$. Error bars indicate SEM.

increased by fluoxetine nor required for behavioral effects of fluoxetine (Holick et al., 2008). Together, the dentate gyrus does not seem to be the critical site for action of fluoxetine in the $\mathrm{BALB} / \mathrm{c}$ strain. Additional investigation of the diversity in effects of antidepressant and anxiolytic drugs in experimental animals would provide important information in revealing neuronal bases for individual differences in reactivity to these drugs in humans.

Serotonergic dysfunction has been implicated in various neurological disorders (Stahl, 1998). Because 5-HT can be released in the CNS in response to changes in environments (Fig. 7) and to other stimuli (Rueter and Jacobs, 1996), dysregulated serotonergic functions may cause aberrant reactivity to external stimuli. Assuming that chronic SSRIs can bidirectionally modify the human central serotonergic system in a manner similar to that observed in the present study, SSRIs may improve both hypofunction and hyperfunction of the serotonergic system by stabilizing the serotonergic synaptic modulation. This hypothesis can explain why SSRIs are applicable to a broad spectrum of neurological disorders. SSRIs have been commonly used to treat anxiety disorders including panic disorder. It has been shown that the hippocampal glucose utilization is associated with panic disorder (Nordahl et al., 1990; Sakai et al., 2006). The robust effect of chronic fluoxetine on the open-field activity observed in the present study may be related to therapeutic effects of SSRIs on panic disorder with agoraphobia, although the lack of significant changes in the anxiety-related behaviors argues against this idea. It has been reported that SSRI can improve symptoms of attention-deficit hyperactivity disorder (ADHD) (Quintana et al., 2007). Polymorphisms of the $5-\mathrm{HT}_{4}$ receptor gene are associated with ADHD ( $\mathrm{Li}$ et al., 2006). We showed that the 5-HTinduced potentiation at the mossy fiber synapse is mediated by $5-\mathrm{HT}_{4}$ receptors. Thus, drugs that could stabilize the serotonergic modulation at the mossy fiber synapse (e.g., 5- $\mathrm{HT}_{4}$ receptor partial agonists) might be effective in treating ADHD and hyperactive symptoms in other psychiatric disorders. This idea is supported by the recent finding that application of the $5-\mathrm{HT}_{4}$ receptor partial agonist 1-(4-amino-5-chloro-2methoxyphenyl)-3-[1-butyl-4-piperidinyl]-1-propanone hydrochloride (RS 67333) in rats induces antidepressant-like effects including a reduction of hyperactivity caused by the olfactory bulbectomy (Lucas et al., 2007). It should also be noted that the effects of RS 67333 developed faster than those of the SSRI cita- lopram. Together, the stabilization of the central serotonergic transmission might play a critical role in behavioral or therapeutic effects of SSRIs and other drugs acting on the serotonergic system.

\section{References}

Airan RD, Meltzer LA, Roy M, Gong Y, Chen H, Deisseroth K (2007) Highspeed imaging reveals neurophysiological links to behavior in an animal model of depression. Science 317:819-823.

Barnes NM, Sharp T (1999) A review of central 5-HT receptors and their function. Neuropharmacology 38:1083-1152.

Benmansour S, Owens WA, Cecchi M, Morilak DA, Frazer A (2002) Serotonin clearance in vivo is altered to a greater extent by antidepressantinduced downregulation of the serotonin transporter than by acute blockade of this transporter. J Neurosci 22:6766-6772.

Bijak M, Tokarski K, Maj J (1997) Repeated treatment with antidepressant drugs induces subsensitivity to the excitatory effect of $5-\mathrm{HT}_{4}$ receptor activation in the rat hippocampus. Naunyn Schmiedebergs Arch Pharmacol 355:14-19.

Chaput Y, de Montigny C, Blier P (1991) Presynaptic and postsynaptic modifications of the serotonin system by long-term administration of antidepressant treatments. An in vivo electrophysiologic study in the rat. Neuropsychopharmacology 5:219-229.

Compan V, Zhou M, Grailhe R, Gazzara RA, Martin R, Gingrich J, Dumuis A, Brunner D, Bockaert J, Hen R (2004) Attenuated response to stress and novelty and hypersensitivity to seizures in $5-\mathrm{HT}_{4}$ receptor knock-out mice. J Neurosci 24:412-419.

Dulawa SC, Holick KA, Gundersen B, Hen R (2004) Effects of chronic fluoxetine in animal models of anxiety and depression. Neuropsychopharmacology 29:1321-1330.

Elswood CJ, Bunce KT, Humphrey PP (1991) Identification of putative $5-\mathrm{HT}_{4}$ receptors in guinea-pig ascending colon. Eur J Pharmacol 196:149-155

Fontana DJ, Daniels SE, Wong EHF, Clark RD, Eglen RM (1997) The effects of novel, selective 5-hydroxytryptamine $(5-\mathrm{HT})_{4}$ receptor ligands in rat spatial navigation. Neuropharmacology 36:689-696.

Haddjeri N, Blier P, de Montigny C (1998) Long-term antidepressant treatments result in a tonic activation of forebrain $5-\mathrm{HT}_{1 \mathrm{~A}}$ receptors. J Neurosci 18:10150-10156.

Henze DA, Wittner L, Buzsáki G (2002) Single granule cells reliably discharge targets in the hippocampal CA3 network in vivo. Nat Neurosci 5:790-795.

Holick KA, Lee DC, Hen R, Dulawa SC (2008) Behavioral effects of chronic fluoxetine in $\mathrm{BALB} / \mathrm{cJ}$ mice do not require adult hippocampal neurogenesis or the serotonin 1A receptor. Neuropsychopharmacology 33:406-417.

Jacobs BL, Azmitia EC (1992) Structure and function of the brain serotonin system. Physiol Rev 72:165-229.

Kenakin T (2003) Ligand-selective receptor conformations revisited: the promise and the problem. Trends Pharmacol Sci 24:346-354.

Kobayashi K, Poo M-m (2004) Spike train timing-dependent associative modification of hippocampal CA3 recurrent synapses by mossy fibers. Neuron 41:445-454.

Kobayashi K, Suzuki H (2007) Dopamine selectively potentiates hippocampal mossy fiber to CA3 synaptic transmission. Neuropharmacology 52:552-561.

Kobayashi K, Manabe T, Takahashi T (1999) Calcium-dependent mechanisms involved in presynaptic long-term depression at the hippocampal mossy fibre-CA3 synapse. Eur J Neurosci 11:1633-1638.

Kobayashi K, Ikeda Y, Suzuki H (2006) Locomotor activity correlates with modifications of hippocampal mossy fibre synaptic transmission. Eur J Neurosci 24:1867-1873.

Leutgeb JK, Leutgeb S, Moser M-B, Moser EI (2007) Pattern separation in the dentate gyrus and CA3 of the hippocampus. Science 315:961-966.

Li J, Wang Y, Zhou R, Wang B, Zhang H, Yang L, Faraone SV (2006) Association of attention-deficit/hyperactivity disorder with serotonin 4 receptor gene polymorphisms in Han Chinese subjects. Neurosci Lett 401:6-9.

Linthorst ACE, Flachskamm C, Holsboer F, Reul JMHM (1994) Local administration of recombinant human interleukin- $1 \beta$ in the rat hippocampus increases serotonergic neurotransmission, hypothalamic-pituitaryadrenocortical axis activity, and body temperature. Endocrinology $135: 520-532$ 
Lucas G, Rymar VV, Du J, Mnie-Filali O, Bisgaard C, Manta S, Lambas-Senas L, Wiborg O, Haddjeri N, Piñeyro G, Sadikot AF, Debonnel G (2007) Serotonin $_{4}\left(5-\mathrm{HT}_{4}\right)$ receptor agonists are putative antidepressants with a rapid onset of action. Neuron 55:712-725.

Lucki I, Dalvi A, Mayorga AJ (2001) Sensitivity to the effects of pharmacologically selective antidepressants in different strains of mice. Psychopharmacology 155:315-322.

Malberg JE, Eisch AJ, Nestler EJ, Duman RS (2000) Chronic antidepressant treatment increases neurogenesis in adult rat hippocampus. J Neurosci 20:9104-9110.

Mlinar B, Pugliese AM, Corradetti R (2001) Selective inhibition of local excitatory synaptic transmission by serotonin through an unconventional receptor in the CA1 region of rat hippocampus. J Physiol (Lond) 534:141-158.

Nordahl TE, Semple WE, Gross M, Mellman TA, Stein MB, Goyer P, King AC, Uhde TW, Cohen RM (1990) Cerebral glucose metabolic differences in patients with panic disorder. Neuropsychopharmacology 3:261-272.

Otmakhov NA, Bragin AG (1982) Effects of norepinephrine and serotonin upon spontaneous activity and responses to mossy fiber stimulation of $\mathrm{CA}_{3}$ neurons in hippocampal slices. Brain Res 253:173-183.

Otmakhova NA, Lewey J, Asrican B, Lisman JE (2005) Inhibition of perforant path input to the CA1 region by serotonin and noradrenaline. J Neurophysiol 94:1413-1422.

Papakostas GI, Fava M, Thase ME (2008) Treatment of SSRI-resistant depression: a meta-analysis comparing within- versus across-class switches. Biol Psychiatry 63:699-704.

Paxinos G, Franklin KBJ (2004) The mouse brain in stereotaxic coordinates, Ed 2. San Diego: Academic.

Quintana H, Butterbaugh GJ, Purnell W, Layman AK (2007) Fluoxetine monotherapy in attention-deficit/hyperactivity disorder and comorbid non-bipolar mood disorders in children and adolescents. Child Psychiatry Hum Dev 37:241-253.

Roychowdhury S, Haas H, Anderson EG (1994) 5- $\mathrm{HT}_{1 \mathrm{~A}}$ and 5- $\mathrm{HT}_{4}$ receptor colocalization on hippocampal pyramidal cells. Neuropharmacology 33:551-557.

Rueter LE, Jacobs BL (1996) A microdialysis examination of serotonin re- lease in the rat forebrain induced by behavioral/environmental manipulations. Brain Res 739:57-69.

Sakai Y, Kumano H, Nishikawa M, Sakano Y, Kaiya H, Imabayashi E, Ohnish T, Matsuda H, Yasuda A, Sato A, Diksic M, Kuboki T (2006) Changes in cerebral glucose utilization in patients with panic disorder treated with cognitive-behavioral therapy. NeuroImage 33:218-226.

Santarelli L, Saxe M, Gross C, Surget A, Battaglia F, Dulawa S, Weisstaub N, Lee J, Duman R, Arancio O, Belzung C, Hen R (2003) Requirement of hippocampal neurogenesis for the behavioral effects of antidepressants. Science 301:805-809.

Segal M (1981) Regional differences in neuronal responses to 5-HT: intracellular studies in hippocampal slices. J Physiol (Paris) 77:373-375.

Stahl SM (1998) Mechanism of action of serotonin selective reuptake inhibitors. Serotonin receptors and pathways mediate therapeutic effects and side effects. J Affect Disord 51:215-235.

Takahashi H, Takada Y, Urano T, Takada A (2002) 5- $\mathrm{HT}_{4}$ receptors in the hippocampus modulate rat locomotor activity. Hippocampus 12:304-310.

Taylor C, Fricker AD, Devi LA, Gomes I (2005) Mechanisms of action of antidepressants: from neurotransmitter systems to signaling pathways. Cell Signal 17:549-557.

Tokarski K, Bijak M (1996) Antidepressant-induced adaptive changes in the effects of $5-\mathrm{HT}, 5-\mathrm{HT}_{1 \mathrm{~A}}$ and $5-\mathrm{HT}_{4}$ agonists on the population spike recorded in hippocampal CA1 cells do not involve presynaptic effects on excitatory synaptic transmission. Pol J Pharmacol 48:565-573.

Vilaró MT, Cortés R, Mengod G (2005) Serotonin 5- $\mathrm{HT}_{4}$ receptors and their mRNAs in rat and guinea pig brain: Distribution and effects of neurotoxic lesions. J Comp Neurol 484:418-439.

Weisskopf MG, Castillo PE, Zalutsky RA, Nicoll RA (1994) Mediation of hippocampal mossy fiber long-term potentiation by cyclic AMP. Science 265:1878-1882.

Ye Y, Jackson K, O’Donnell JM (2000) Effects of repeated antidepressant treatment of type $4 \mathrm{~A}$ phosphodiesterase (PDE4A) in rat brain. J Neurochem 74:1257-1262.

Yoshioka M, Matsumoto M, Numazawa R, Togashi H, Smith CB, Saito H (1995) Changes in the regulation of 5-hydroxytryptamine release by $\alpha_{2}$ adrenoceptors in the rat hippocampus after long-term desipramine treatment. Eur J Pharmacol 294:565-570. 